\title{
Economic Assessment of Power Grid Development Using Artificial Bee Colony Algorithm
}

\author{
Arif Nur Afandi ${ }^{1,2,3^{*}}$, Aji P. Wibawa1', Syaad Patmantara1', Goro Fujita ${ }^{4}$, Slamet Hani ${ }^{5}$, \\ Yunis Sulistyowati ${ }^{6}$
}

\footnotetext{
${ }^{1}$ Electrical Engineering Department, Universitas Negeri Malang, 551312 Malang, P.O.B. 0341, Indonesia

2 Smart Power and Advanced Energy Systems (SPAES) Center, 65322 Batu, Jl. Hasanudin, WA A 33, Indonesia

${ }^{3}$ Center of Advanced Material for Renewable Energy, PUI-PT, Universitas Negeri Malang, 551312 Malang, P.O.B. 0341, Indonesia

${ }^{4}$ Electrical Engineering, Shibaura Institute of Technology, 108-8548 Tokyo, 3-9-14 Shibaura, Minato-ku, 3 Chome-7-5 Toyosu, Japan

${ }^{5}$ Electrical Engineering, Institut Teknologi AKPRID, 55222 Yogyakarta, 28 Jl. Kalisahak, Kompleks Balapan, Indonesia

${ }^{6}$ Mathematics Department, IKIP Budi Utomo, 65119 Malang, 14B Jl. Simpang Arjuno, Indonesia

*Corresponding author, e-mail: an.afandi@um.ac.id
}

Received: 24 April 2021, Accepted: 04 July 2021, Published online: 10 January 2022

\begin{abstract}
The electricity system is generally rapidly developing for covering various power demands with requiring a reliable and safe supply where the substructures are expanding further in generation systems, transmission systems, and distribution systems. However, the system must be run economically to access energy at a cost-effective level related to existing energy enterprises and energy consumption in the load which is represented periodically in the total costs of operations for all operating units. As a basis for its determination, the transmission of economic power within the technical limits applicable is taken into consideration. Environmental factors, on the other hand, are also an impediment to technical limitations. As a result, the operation's economic measure is expressed in the process of providing and selling energy to customers. These works use the Artificial Bees Colony algorithm to determine the scheduling of generating units using the basic principle of optimization to describe its relationship as an economic function. The IEEE-30 bus system is used as a basic model for system development. The analysis' findings show that the weighting factor scheme has an impact on the minimum total cost and that the combination of the electricity distribution process and environmental factors has implications for the operational financial condition and electricity production. The power output, in particular, is proportional to the cost of each generating unit.
\end{abstract}

Keywords

algorithm, economic, dispatch, power, optimal

\section{Introduction}

Maintaining an energy balance between energy providers and users is one of the most important aspects of an electric power system. This is why the power plant must be able to provide energy consistently to meet the load requirements at all times. The electric power system can be described in simple terms as a simple relationship between the generating unit and the energy users, which is currently evolving into a large grid electric power system with many interconnected physical parts $[1,2]$. This system has evolved rapidly with the advancement of electrical technology, incorporating various connections at various voltage levels into an integrated system. The power system, on the other hand, has begun to integrate various types of generating systems to meet the energy needs of load centers located across multiple regions [3-5]. Furthermore, the system can be configured in a variety of ways depending on the requirements, though it can generally be divided into subsections based on its function. In general, a power system structure is developed using an interconnection network to connect and channel electrical energy from the generator location to the demand area. For example, the Java Bali Power Grid (JBPG) is linked to the Malang Raya City Power Grid (MRCPG) and is used to integrate all voltage levels in systems that interconnect loads and generators, where this condition is operated in isolation. Furthermore, this system is run using strategies 
that use the least amount of fuel. The least-cost approach leads to the inclusion of financial consideration in power generation. Furthermore, this condition necessitates the selection of the appropriate combination for all power generation units involved in service operations for a full day to maintain system balance and adequacy $[6,7]$.

Furthermore, the power plants are operated following their requirements and the schedule established as a guide for daily operations. Hydro, gas, steam, and other power plants are among the integrated plants in this system. The power system has been integrated into an existing system. When combining different types of power plants to support the load, it's critical to keep the selection and scheduling of operations in mind. As a result, the operation of this device entails precise measurement and division for the composition of each power plant [7-9]. As seen in the load dispatch optimization, optimization is also one of the strategic measures to decide the loading for each electricity generation unit, so that the process remains in optimal and cost-effective conditions (OCEC). The MRCPG, as part of the JBPG, should be run economically concerning the OCEC problem. The OCEC problem, which is defined as an optimal scheduled generating unit for contributing in the portion of the unit commitment for power production while supplying the load demand, is one of the most important concerns in power system operations and planning [10-12].

Global warming has received a lot of attention in recent years. As a result, many attempts have been made to reduce the global temperature increase. So that early on, weather conditions at critical stages of global warming can be tracked. This environmental necessity is exacerbated by the rising temperature on Earth as a result of various human activities [8, 13, 14]. According to the processing activities, one of the contributors is linked to the power system's activity. In this situation, the power system's activity contributes to global warming by releasing contaminants into the air. By taking this into account, the JBPG and MRCPG have also been penetrated to keep pollutant discharge as an environmental impact when firing thermal power plants, and these results have also been evaluated.

Currently, the pollutant discharged into the air is referred to as an Emission Optimization (EO) and is associated with thermal power plants. In terms of financial performance, this problem is also integrated into the MRCPG's generating unit performance. Furthermore, environmental requirements for inclusion in the existing operation imposed technical constraints and operational limitations. Meanwhile, when the EO is taken into account, the OCEC problem becomes more difficult. Both problems are expressed in the Integrated Economic Optimization (IEO) model, which can be applied to MRCPG development and solved using a variety of computations.

Many works on the OCEC have been proposed, with mathematical programming and optimization techniques being used to replace traditional techniques. Previously, this traditional approach was commonly applied to a variety of cases, with slight variations in the application in related cases. As a result, this time-honored technique was frequently used. Smart computations, which are composed of smart techniques such as evolutionary algorithms to determine an optimal solution, have recently become alternative ways of solving problems [14-16]. In line with the development of various types of computing applications, the intelligent calculation is becoming increasingly popular and widely used in various technical issues. Furthermore, the method's approach is flexible, allowing it to be applied to complex systems or models with a variety of variables. As a result, the use of intelligent computation is becoming more common. Furthermore, many novel evolutionary methods have been introduced, such as the Artificial Bee Colony (ABC), which is a novel method that can be applied to technical problems. $\mathrm{ABC}$ can be easily applied to complex optimizations, such as OCEC and IEO, as a potential procedure.

\section{Developing approach}

The OCEC problem is mathematically related to a nonlinear equation model. Various parameters that have been modeled from existing systems can be used to compile the OCEC in general [17-20]. Where the variables in the real system have been defined as dominant and non-dominant components, or even components that need to be ignored for OCEC, using certain approaches. The OCEC and EO issues are mentioned concerning the IEO issue. Also, as in, a total transmission loss is approached. The OCEC problem is mathematically related to a nonlinear equation model. Various parameters that have been modeled from existing systems can be used to compile the OCEC in general $[12,21]$. Where the variables in the real system have been defined as dominant and non-dominant components, or even components that need to be ignored for OCEC, using certain approaches. The OCEC and EO issues are mentioned in the IEO issue.

Besides, as in, a total transmission loss is approached. This diagram depicts the connection's development model in various areas. In terms of topology, this model is based on the IEEE-30 model (see Fig. 1). To determine the optimal 
scheduled generating units, the $\mathrm{ABC}$ algorithm is used to search for the IEO's total minimum costs based on random candidate food source solutions. The IEEE-30 bus system model will be used to run it. The IEEE-30 bus system model is used as the basic network architecture in the system creation process, so the network link is an extension of the current system structure referering to Fig. 2. This standard type, on the other hand, encourages the implementation of a development strategy and the expansion of the network framework that has been used to accommodate all potential increases in electricity demand as well as the addition of power generation units [7, 14, 22].

An evolutionary method is useful for intelligent computation, as previously stated. The system is also run on an $\mathrm{ABC}$ algorithm based on food sources in this work. More specifically, $\mathrm{ABC}$ is used to find and determine the most

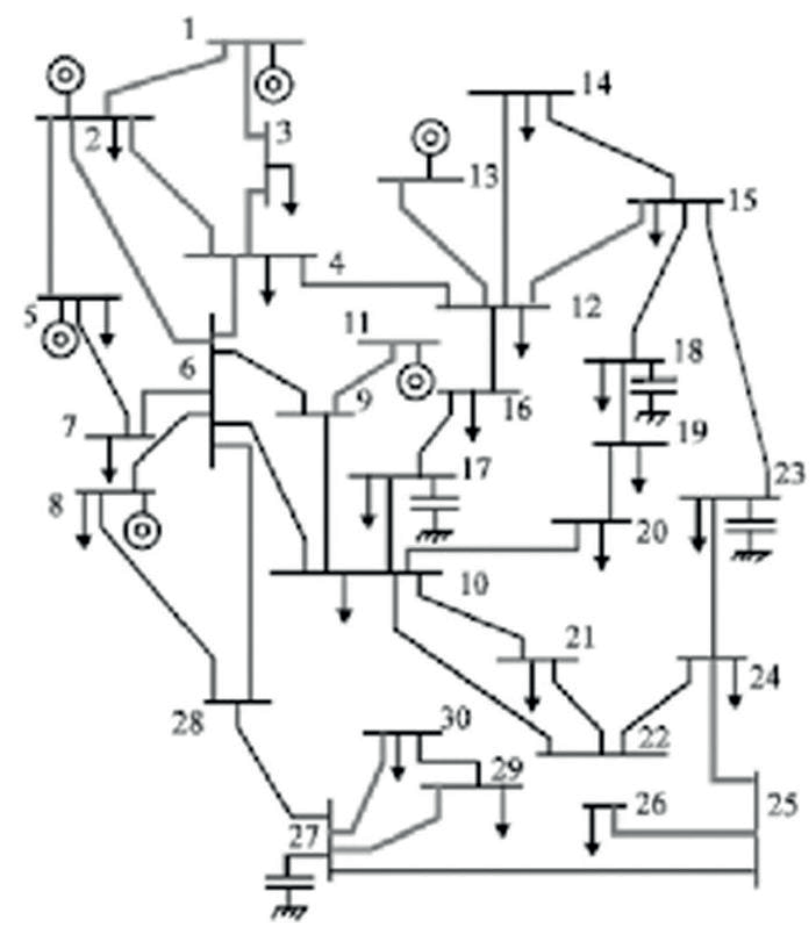

Fig. 1 IEEE 30 bus system model

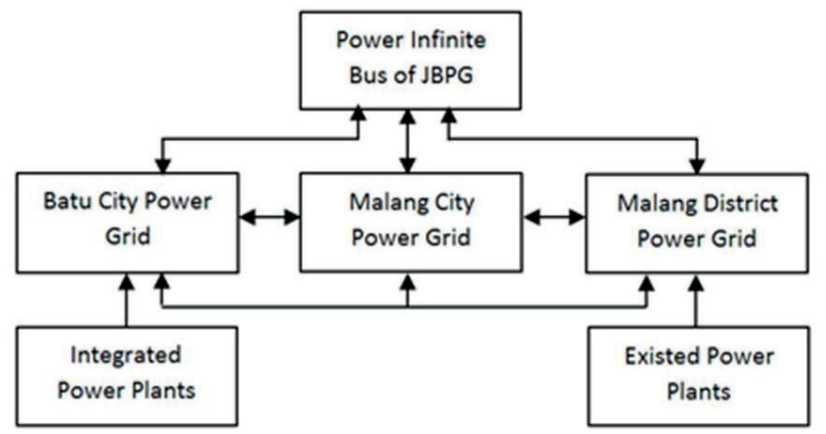

Fig. 2 MRCPG development model appropriate combination for the IEO problem while taking into account all of the constraints. All processes in finding optimal solutions are carried out based on existing processes, in terms of the $\mathrm{ABC}$ hierarchy and procedures, with its computational intelligence function. Additionally, $\mathrm{ABC}$ processes are mentioned. Furthermore, IEO is approached using a nonlinear equation as an objective function, which is expressed as a total cost for supplying total power from generation stations with a pollutant emission constraint as a constraint. The burning of fossil fuels in thermal power plants has produced a variety of pollutants. A price penalty and a weighting factor are also included in the IEO. For the given load, the penalty factor displays the rate coefficient of each generating unit at its maximum output. The compromised factor depicts a financial and emission contribution that is shared. In general, the problem can be formulated by using expressions as follows:

$$
\begin{aligned}
& \text { OECE minimize } F_{t c}=\sum_{i=1}^{n g}\left(c_{i}+b_{i} \cdot P_{i}+a_{i} \cdot P_{i}^{2}\right), \\
& \text { EO minimze } E_{t}=\sum_{i=1}^{n g}\left(\gamma_{i}+\beta_{i} \cdot P_{i}+\alpha_{i} \cdot P_{i}^{2}\right), \\
& h_{i}=\frac{F_{i}\left(P_{i}^{\max }\right) / P_{i}^{\max }}{E_{i}\left(P_{i}^{\max }\right) / P_{i}^{\max }},
\end{aligned}
$$

$V_{p}^{\min } \leq V_{p} \leq V_{p}^{\max }$,

where $P_{i}$ is the output power of $i^{\text {th }}$ generating unit (MW), $a_{i}$, $b_{i}, c_{i}$ are fuel cost coefficients of $i^{\text {th }}$ generating unit, $F_{t c}$ is total fuel cost $(\$ / \mathrm{h}), \alpha_{i}, \beta_{i}, \gamma_{i}$ are emission coefficients of $i^{\text {th }}$ generating unit, $E_{t}$ is total emission of generating units $(\mathrm{kg} / \mathrm{h})$, $h_{i}$ is individual penalty factor of $i^{\text {th }}$ generating unit, $P_{i}^{\max }$ is the maximum output power of ith generating unit, $E_{i}$ is total emission of $i^{\text {th }}$ generating unit $(\mathrm{kg} / \mathrm{h}), F_{i}$ is fuel cost of $i^{\text {th }}$ generating unit $(\$ / \mathrm{h}), \Phi$ is $\operatorname{CEED}(\$ / \mathrm{h}), w$ is compromised factor, $n g$ is the number of the generator, $h$ is penalty factor of 
ascending order selection of $h_{i}, P_{D}$ is power load demand, $P_{L}$ is transmission loss, $P_{G p}$ and $Q_{G p}$ are power injections of load flow at bus $p, P_{D p}$ and $Q_{D p}$ are load demands of load flow at bus $p, V_{p}$ and $V_{q}$ are voltages at bus $p$ and $q, P_{i}^{\min }$ is minimum power of $i^{\text {th }}$ generating unit, $Q_{i}^{\max }$ and $Q_{i}^{\min }$ are maximum and minimum reactive powers of $i^{\text {th }}$ generating unit, $V_{p}^{\max }$, and $V_{p}^{\text {min }}$ are maximum and minimum voltages at bus $p$.

\section{Technical procedure}

Furthermore, all data define the system and its operating conditions, allowing it to be understood or simulated following the desired scenario. The IEO software protects OCEC, EO, weighting factor, penalty factor, and restrictions. All components of the IEO are combined into a function that is limited to different conditions and parameters as an optimization goal to determine the most cost-effective activity associated with the ABC phases [5, 14, 22]. Fig. 1 depicts the IEEE-30 bus system, which is used to illustrate the positions of generating units and load buses and to present an existing developed system with technical parameters. The ABC algorithm is presented in detail by some pseudo-code sequencing phases, with the sequencing computational order for solving the IEO problem shown in Fig. 3.

As detailed in Tables 1 to 3, the study's system parameters are shown in this section in several matters directly related to the problem. These studies are aimed at determining the lowest costs through optimization using IEO's weighting factor scenario. The primary goal of the weighting factor

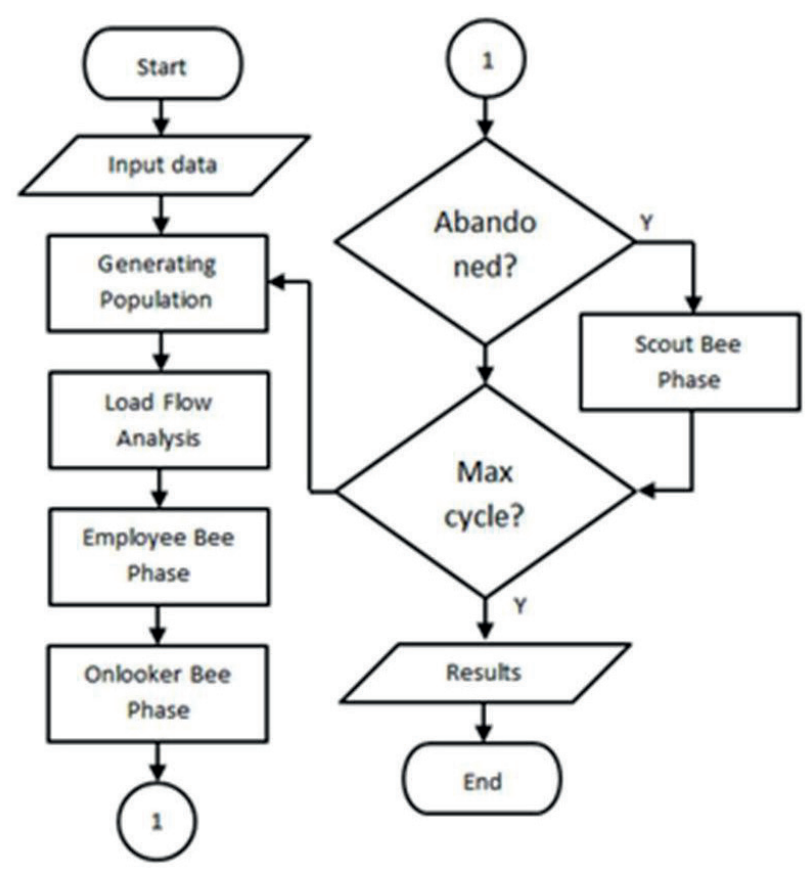

Fig. 3 Sequencing orders of ABC's computation
Table 1 Load data for each bus

\begin{tabular}{lccccc}
\hline Bus & MW & Mvar & Bus & MW & Mvar \\
\hline 1 & 0.0 & 0.0 & 16 & 3.5 & 1.8 \\
2 & 21.7 & 12.7 & 17 & 9.0 & 5.8 \\
3 & 2.4 & 1.2 & 18 & 3.2 & 0.9 \\
4 & 7.6 & 1.6 & 19 & 9.5 & 3.4 \\
5 & 94.2 & 19.0 & 20 & 2.2 & 0.7 \\
6 & 0.0 & 0.0 & 21 & 17.5 & 11.2 \\
7 & 22.8 & 10.9 & 22 & 0.0 & 0.0 \\
8 & 30.0 & 30.0 & 23 & 3.2 & 1.6 \\
9 & 0.0 & 0.0 & 24 & 8.7 & 6.7 \\
10 & 5.8 & 2.0 & 25 & 0.0 & 0.0 \\
11 & 0.0 & 0.0 & 26 & 3.5 & 2.3 \\
12 & 11.2 & 7.5 & 27 & 0.0 & 0.0 \\
13 & 0.0 & 0.0 & 28 & 0.0 & 0.0 \\
14 & 6.2 & 1.6 & 29 & 2.4 & 0.9 \\
15 & 8.2 & 2.5 & 30 & 10.6 & 1.9 \\
\hline
\end{tabular}

Table 2 Fuel cost coefficients and power limits

\begin{tabular}{lccccc}
\hline & \multicolumn{2}{c}{ Fuel cost coefficients } & \multicolumn{2}{c}{ Power limits } \\
\cline { 2 - 6 } Gen & $\mathrm{a}\left(\$ / \mathrm{MWh}^{2}\right)$ & $\mathrm{b}(\$ / \mathrm{MWh})$ & $\mathrm{c}$ & $\begin{array}{c}P^{\min } \\
(\mathrm{MW})\end{array}$ & $\begin{array}{c}P^{\max } \\
(\mathrm{MW})\end{array}$ \\
\hline G1 & 0.00375 & 2.00000 & 0 & 50 & 200 \\
G2 & 0.01750 & 1.75000 & 0 & 20 & 80 \\
G3 & 0.06250 & 1.00000 & 0 & 15 & 50 \\
G4 & 0.00835 & 3.25000 & 0 & 10 & 35 \\
G5 & 0.02500 & 3.00000 & 0 & 10 & 30 \\
G6 & 0.02500 & 3.00000 & 0 & 12 & 40 \\
\hline
\end{tabular}

Table 3 Emission coefficients

\begin{tabular}{cccc}
\hline \multirow{3}{*}{ Gen } & \multicolumn{3}{c}{ Emission coefficients } \\
\cline { 2 - 4 } & $\alpha\left(\mathrm{kg} / \mathrm{MWh}^{2}\right)$ & $\beta(\mathrm{kg} / \mathrm{MWh})$ & $\gamma$ \\
\hline G1 & 0.0126 & -1.1000 & 22.983 \\
G2 & 0.0200 & -0.1000 & 25.313 \\
G3 & 0.0270 & -0.0100 & 25.505 \\
G4 & 0.0291 & -0.0050 & 24.900 \\
G5 & 0.0290 & -0.0040 & 24.700 \\
G6 & 0.0271 & -0.0055 & 25.300 \\
\hline
\end{tabular}

is to find the best combination of OCEC and EO problems that will result in the lowest cost of all possible weighting factor combinations, as shown in Table 4. These schemes are also used to find the best composition of scheduled generating units using the $\mathrm{ABC}$ algorithm based on the optimal solution for reducing pollutant discharges and operating costs associated with loads as shown in Table 1 by taking into account the weighting factor.

\section{Result and discussion}

In these studies, MRCPG development is focused on the cost-effectiveness of connecting all existing and integrated 
Table 4 Computational schemes

\begin{tabular}{ccccccc}
\hline & \multicolumn{5}{c}{ Weighting factor } \\
\cline { 2 - 7 } Types & \multicolumn{2}{c}{ WF1 } & \multicolumn{2}{c}{ WF2 } & \multicolumn{2}{c}{ WF3 } \\
\cline { 2 - 7 } & $\mathrm{w}_{\mathrm{eco}}$ & $\mathrm{w}_{\mathrm{emi}}$ & $\mathrm{w}_{\mathrm{eco}}$ & $\mathrm{w}_{\mathrm{emi}}$ & $\mathrm{w}_{\mathrm{eco}}$ & $\mathrm{w}_{\mathrm{emi}}$ \\
\hline IEO1 & 1 & 0 & 1 & 0 & 0 & 1 \\
IEO2 & 0.7 & 0.3 & 1 & 0.3 & 0.3 & 1 \\
IEO3 & 0.5 & 0.5 & 1 & 0.5 & 0.5 & 1 \\
IEO4 & 0.3 & 0.7 & 1 & 0.7 & 0.7 & 1 \\
IEO5 & 0 & 1 & 1 & 1 & 1 & 1 \\
\hline
\end{tabular}

power plants using a standard power system model. The IEO is subjected to the preceding section to cover all related financial and environmental functions [23-25]. Furthermore, $\mathrm{ABC}$ is used to optimize processes while determining the best solution. This algorithm, based on Table 3 , shows three case studies to demonstrate the IEO's performance using weighting factors $[12,26]$. WF1 is applied to the objective function to demonstrate OCEC or EO dominance. WF2 and WF3 are used in simulations to describe the component's contribution to the objective function. IEO used $\mathrm{w}_{\text {eco }}=1$ and $\mathrm{w}_{\mathrm{emi}}=0$ to express pure OCEC, IEO used $\mathrm{w}_{\mathrm{eco}}=0$ and $\mathrm{w}_{\mathrm{emi}}=1$ to express pure EO, and IEO used $\mathrm{w}_{\text {eco }}=1$ and $\mathrm{w}_{\mathrm{emi}}=1$ to express full IEO. Table 3 lists all of the weighting factors. To show contributors to the operator, three schemes are used. WF1 shows defined portions, WF2 shows OCEC dominance, and WF3 shows pollutant penetrations.

Tables 5 and 6 show the IEO results for 283.4 MW and 126.2 MVar of load demand, respectively. Tables 5 and 6 depict technical performance based on the best possible combination of individual system contributions. Table 5 shows that each scenario has a variety of operational implications. Each result in Table 6 is aimed at achieving optimal conditions based on the load's power consumption. Furthermore, these results frequently show optimum conditions as a result of the optimization method using computation. These findings are thus ideal operating conditions, taking technological and economic factors into account, where the ABC's performance is not discussed, even though its speed is depicted in Fig. 4 with fast and stable convergence during the determination of the optimal solution. To put it another way, this research has a fast convergence characteristic for the speed applied to the IEO problem as a single function of the problem based on OCEC and EO needed on various constraints.

Even though the outcomes of each scenario differ, optimization has produced the best possible results within the technical constraints. Furthermore, the problem, as well as the findings, are directly related to the research findings in several ways. As a result, these studies are aimed at determining minimum costs through optimization using IEO's weighting factor scenario. Economic and environmental factors are combined in one optimization function with these considerations, resulting in an optimal solution for both, as shown in Table 5 for power production. As a result, the findings support the system's economic operating decisions at work. It can be seen from the numerical results in Table 5 that each generating unit is scheduled in different output power with different financial usage for producing power. In terms of the system's power loss, it consumes a variety of power on the line, as shown in Fig. 5 where the emission is discharged in Fig. 6.

Table 5 Power unit commitment

\begin{tabular}{|c|c|c|c|c|c|c|c|c|}
\hline \multirow{2}{*}{\multicolumn{2}{|c|}{ Schemes }} & \multicolumn{7}{|c|}{ Power Productions (MW) } \\
\hline & & \multirow{2}{*}{$\frac{\mathrm{G} 1}{186.26}$} & \multirow{2}{*}{$\frac{\mathrm{G} 2}{65.38}$} & \multirow{2}{*}{$\frac{\text { G3 }}{27.87}$} & \multirow{2}{*}{$\frac{\mathrm{G} 4}{33.71}$} & \multirow{2}{*}{$\frac{\text { G5 }}{24.45}$} & \multirow{2}{*}{$\frac{\text { G6 }}{36.00}$} & \multirow{2}{*}{$\frac{\text { Total }}{373.67}$} \\
\hline \multirow{5}{*}{ WF1 } & IEO1 & & & & & & & \\
\hline & IEO2 & 152.46 & 75.21 & 38.27 & 31.33 & 22.95 & 31.87 & 352.09 \\
\hline & IEO3 & 151.55 & 63.48 & 31.80 & 31.87 & 29.63 & 37.13 & 345.46 \\
\hline & IEO4 & 131.45 & 61.39 & 40.27 & 31.80 & 29.08 & 39.09 & 333.08 \\
\hline & IEO5 & 133.69 & 59.88 & 34.26 & 34.58 & 30.00 & 33.30 & 325.71 \\
\hline \multirow{5}{*}{ WF2 } & IEO1 & 193.26 & 73.38 & 40.87 & 33.71 & 22.45 & 24.00 & 387.67 \\
\hline & IEO2 & 167.85 & 62.27 & 27.36 & 30.78 & 28.23 & 29.94 & 346.43 \\
\hline & IEO3 & 149.24 & 71.13 & 46.70 & 31.51 & 28.68 & 28.70 & 355.96 \\
\hline & IEO4 & 143.72 & 70.87 & 34.70 & 31.76 & 28.20 & 35.45 & 344.70 \\
\hline & IEO5 & 147.56 & 66.48 & 36.80 & 34.87 & 26.63 & 36.13 & 348.47 \\
\hline \multirow{5}{*}{ WF3 } & IEO1 & 129.69 & 67.88 & 44.26 & 33.58 & 30.00 & 35.30 & 340.71 \\
\hline & IEO2 & 138.50 & 60.98 & 40.12 & 32.72 & 29.73 & 31.91 & 333.96 \\
\hline & IEO3 & 130.46 & 69.58 & 40.85 & 31.83 & 29.73 & 37.67 & 340.12 \\
\hline & IEO4 & 145.09 & 66.03 & 35.89 & 33.88 & 27.83 & 37.56 & 346.28 \\
\hline & IEO5 & 137.56 & 62.48 & 39.80 & 34.87 & 26.63 & 32.13 & 333.47 \\
\hline
\end{tabular}


Table 6 Operating cost of the operation

\begin{tabular}{rcccc}
\hline \multirow{2}{*}{ Schemes } & \multicolumn{3}{c}{ Financial consumptions $(\$ / \mathrm{h})$} \\
\cline { 2 - 4 } WF1 & IEO1 & 424.24 & $1,115.99$ & $1,540.23$ \\
& IEO2 & 367.19 & $1,065.54$ & $1,432.73$ \\
& IEO3 & 348.38 & $1,034.59$ & $1,272.97$ \\
& IEO4 & 321.98 & $1,018.35$ & $1,340.33$ \\
& IEO5 & 310.79 & 972.05 & $1,282.84$ \\
& IEO1 & 461.00 & $1,179.89$ & $1,640.89$ \\
& IEO2 & 363.64 & $1,017.12$ & $1,380.76$ \\
WF2 & IEO3 & 369.23 & $1,102.02$ & $1,471.25$ \\
& IEO4 & 346.80 & $1,040.66$ & $1,387.46$ \\
& IEO5 & 352.14 & $1,054.02$ & $1,406.16$ \\
& IEO1 & 335.99 & $1,056.67$ & $1,392.66$ \\
IEO2 & 324.98 & $1,009.20$ & $1,334.18$ \\
WF3 & IEO3 & 335.43 & $1,048.06$ & $1,383.49$ \\
IEO4 & 347.23 & $1,047.87$ & $1,395.10$ \\
IEO5 & 325.11 & $1,005.84$ & $1,330.95$ \\
\hline
\end{tabular}

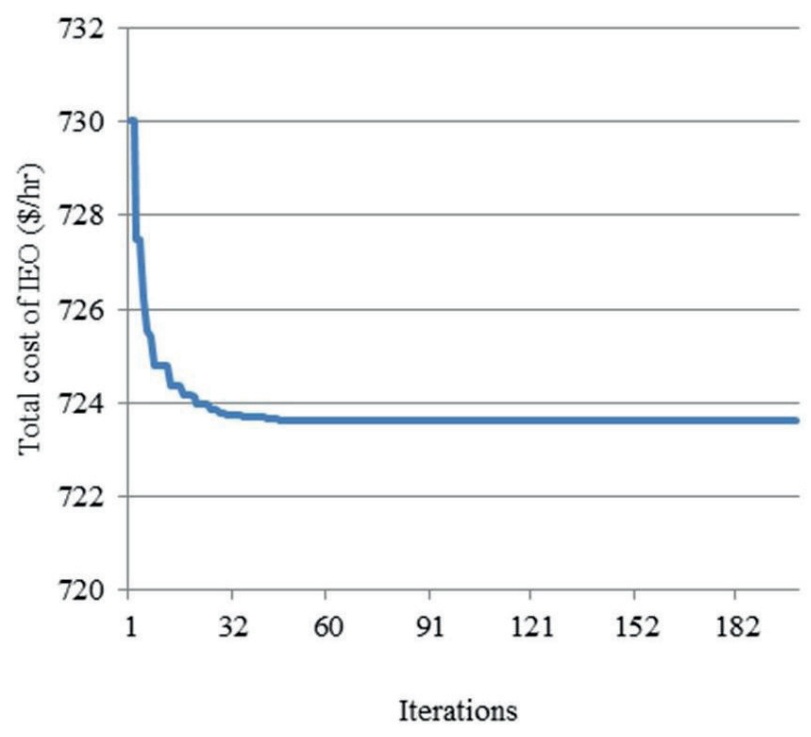

Fig. 4 Convergence speed of IEO3 with $\mathrm{w}_{\mathrm{eco}}=0.5$ and $\mathrm{w}_{\mathrm{emi}}=0.5$

In terms of computation, the $\mathrm{ABC}$ application employs 0.5 of the equivalence weighting factor, arriving at a minimum point of $\$ 723.63$ per hour after 45 iterations after starting at $\$ 730.03$ per hour. Running computing also shows that after starting at $\$ 810.71$ / hour, pure ED needs 26 iterations to get an $\$ 801.72$ / hour solution from IEO1. To get from \$ 1460.68 / hour to $\$ 1447.30$ / hour, the complete IEO, IEO5, requires 38 iterations. Table 5 shows the actual results based on economic operations for financial consumption and emission compensation for each scheme. Table 4 provides concrete results for committed power output in terms of power production. In comparison to other strategies, the weighting factor of equality has a lower cost. Based on these findings, it appears that MRCPG should operate using IEO3 from WF1.

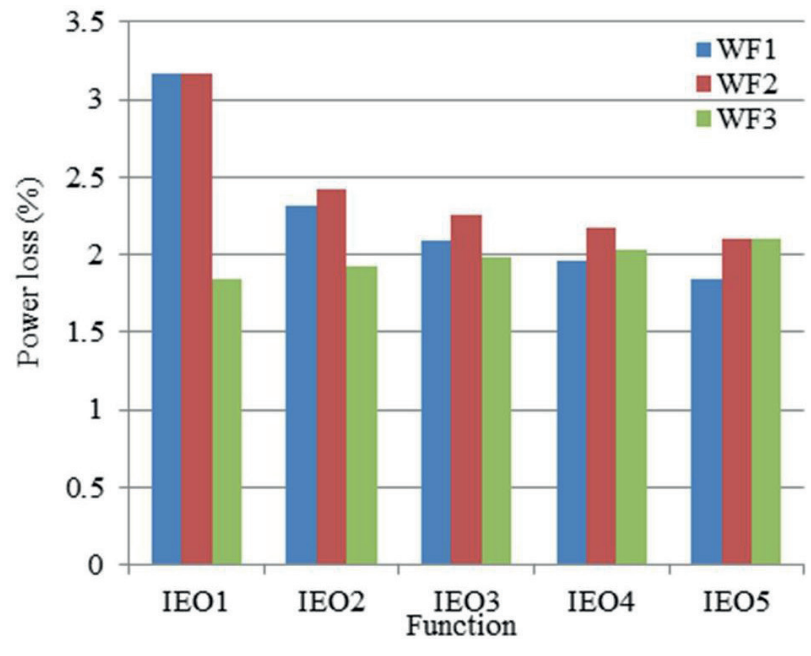

Fig. 5 Power loss of the various scheme for the IEO

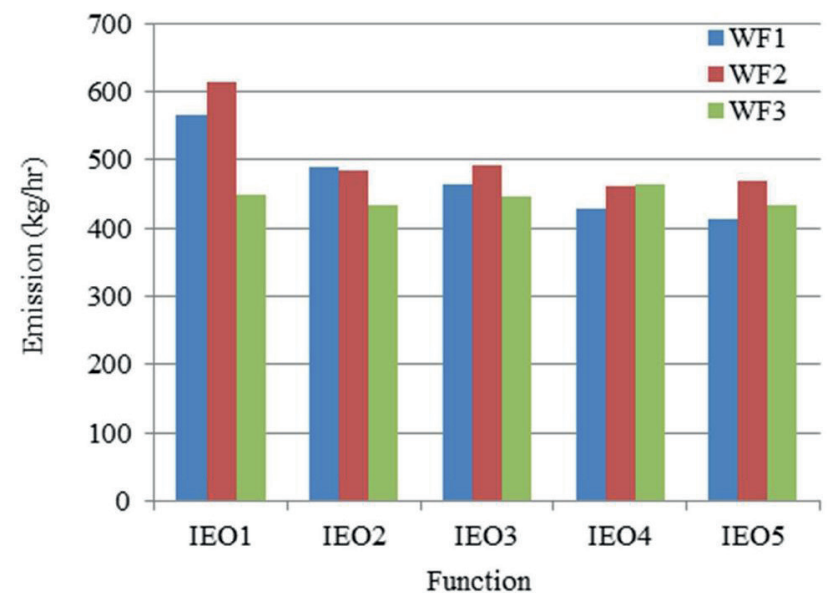

Fig. 6 Emission discharge accumulation

MRCPG is also designed as an IEEE-30 bus system, with power plants distributed across multiple locations. Demand is also designed and placed in this development, as shown in Fig. 2. The weighting factor is used to find the best combination of OCEC and EO problems with the lowest cost of all possible weighting factor combinations.

\section{Conclusion}

Table 4 provides concrete results for committed power output in terms of power production. In comparison to other strategies, the weighting factor of equality has a lower cost. Based on these findings, it appears that MRCPG should operate using IEO3 from WF1. MRCPG is also designed as an IEEE-30 bus system, with power plants distributed across multiple locations. Demand is also designed and placed in this development, as shown in Fig. 2. The weighting factor is used to find the best combination of OCEC and EO problems with the lowest cost of all possible weighting factor combinations. 


\section{References}

[1] Cross, S., Padfield, D., Ant-Wuorinen, R., King, P., Syri, S. "Benchmarking island power systems: Results, challenges, and solutions for long term sustainability", Renewable and Sustainable Energy Reviews, 80, pp. 1269-1291, 2017.

https://doi.org/10.1016/J.RSER.2017.05.126

[2] Emmanuel, M., Doubleday, K., Cakir, B., Marković, M., Hodge, B. M. "A review of power system planning and operational models for flexibility assessment in high solar energy penetration scenarios", Solar Energy, 210, pp. 169-180, 2020. https://doi.org/10.1016/J.SOLENER.2020.07.017

[3] Conte, F., Massucco, S., Paolone, M., Schiapparelli, G. P., Silvestro, F., Zuo, Y. "Frequency stability assessment of modern power systems: Models definition and parameters identification", Sustainable Energy, Grids and Networks, 23, Article number: 100384, 2020. https://doi.org/10.1016/J.SEGAN.2020.100384

[4] Afandi, A. N., Fadlika, I., Gumilar, L. "Power Flow Analysis of Power System Topology Development for Advancing Electricity System of Local Interconnection", In: The 4th International Conference on Science and Technology, (ICST), Yogyakarta, Indonesia, 2018, pp. 1-6 https://doi.org/10.1109/ICSTC.2018.8528690

[5] Arengga, D., Agustin, W., Rahmawati, Y., Sendari, S., Afandi, A. N. "SPEKTRA fast and smart software for renewable energy management", IOP Conference Series: Earth and Environmental Science, 105, Article number: 012077, 2018. https://doi.org/10.1088/1755-1315/105/1/012077

[6] Basu, M. "Multi-region dynamic economic dispatch of solar-windhydro-thermal power system incorporating pumped hydro energy storage", Engineering Applications of Artificial Intelligence, 86, pp. 182-196, 2019.

https://doi.org/10.1016/J.ENGAPPAI.2019.09.001

[7] Pattanaik, J. K., Basu, M., Dash, D. P. "Improved real coded genetic algorithm for dynamic economic dispatch", Journal of Electrical Systems and Information Technology, 5(3), pp. 349-362, 2018. https://doi.org/10.1016/J.JESIT.2018.03.002

[8] Feng, C., Shao, C., Wang, X. "CSP clustering in unit commitment for power system production cost modeling", Renewable Energy, 168, pp. 1217-1228, 2021.

https://doi.org/10.1016/J.RENENE.2020.12.096

[9] Lin, C., Wu, W., Wang, B., Shahidehpour, M., Zhang, B. "Joint Commitment of Generation Units and Heat Exchange Stations for Combined Heat and Power Systems", IEEE Transactions on Sustainable Energy, 11(3), pp. 1118-1127, 2020. https://doi.org/10.1109/TSTE.2019.2917603

[10] Niu, T., Hu, B., Xie, K., Pan, C., Jin, H., Li, C. "Spacial coordination between data centers and power system considering uncertainties of both source and load sides", International Journal of Electrical Power \& Energy Systems, 124, Article number: 106358, 2021. https://doi.org/10.1016/J.IJEPES.2020.106358

[11] Kumar Mishra, S., Kumar Mishra, S. "A Comparative Study of Solution of Economic Load Dispatch Problem in Power Systems in the Environmental Perspective", Procedia Computer Science, 48, pp. 96-100, 2015.

https://doi.org/10.1016/J.PROCS.2015.04.156
[12] Afandi, A. N., Miyauchi, H. "Harvest Season Artificial Bee Colony, Superior Performances on Combined Economic and Emission Dispatch of Power System", International Journal of Computer and Electrical Engineering, 5(6), pp. 538-544, 2013. https://doi.org/10.7763/IJCEE.2013.V5.768

[13] Shao, Z., Si, F., Wu, H., Tong, X. "An agile and intelligent dynamic economic emission dispatcher based on multi-objective proximal policy optimization", Applied Soft Computing, 102, Article number: 107047, 2021.

https://doi.org/10.1016/J.ASOC.2020.107047

[14] Silva, J. C., Zamora, A., Paternina, M. R. A., Mejia-Ruiz, G. E. "An Adaptable Hybrid Optimization Algorithm for Solving the Economic and Emission Dispatch Problem", In: 2019 IEEE PES Innovative Smart Grid Technologies Conference - Latin America (ISGT Latin America), Gramado City, Brazil, 2019, pp. 1-6. https://doi.org/10.1109/ISGT-LA.2019.8895495

[15] Qian, S., Wu, H., Xu, G. "An improved particle swarm optimization with clone selection principle for dynamic economic emission dispatch", Soft Computing, 24(20), pp. 15249-15271, 2020. https://doi.org/10.1007/s00500-020-04861-4

[16] Afandi, A. N., Aji Prasetya, W., Padmantara, S., Aripriharta, Sulistyorini, Y. "Mathematical approach of natural mechanism for exploring structures of evolutionary algorithm", AIP Conference Proceedings, 2014(1), Article number: 020161, 2018. https://doi.org/10.1063/1.5054565

[17] Saavedra-Moreno, B., Salcedo-Sanz, S., Paniagua-Tineo, A., Prieto, L., Portilla-Figueras, A. "Seeding evolutionary algorithms with heuristics for optimal wind turbines positioning in wind farms", Renewable Energy, 36(11), pp. 2838-2844, 2011.

https://doi.org/10.1016/j.renene.2011.04.018

[18] Hanh, P. T. H., Thanh, P. D., Binh, H. T. T. "Evolutionary algorithm and multifactorial evolutionary algorithm on clustered shortest-path tree problem", Information Sciences, 553, pp. 280-304, 2021.

https://doi.org/10.1016/j.ins.2020.10.024

[19] Mahmoud, K., Abdel-Nasser, M., Mustafa, E., Ali, Z. M. "Improved Salp-Swarm Optimizer and Accurate Forecasting Model for Dynamic Economic Dispatch in Sustainable Power Systems", Sustainability, 12(2), Article number: 576, 2020. https://doi.org/10.3390/su12020576

[20] Afandi, A. N., Fadlika, I., Andoko, A. "Comparing Performances of Evolutionary Algorithms on the Emission Dispatch and Economic Dispatch Problem", TELKOMNIKA (Telecommunication Computing Electronics and Control), 13(4), Article number: 1187, 2015. https://doi.org/10.12928/TELKOMNIKA.V13I4.3166

[21] Aslan, S., Karaboga, D., Badem, H. "A new artificial bee colony algorithm employing intelligent forager forwarding strategies", Applied Soft Computing, 96, Article number: 106656, 2020. https://doi.org/10.1016/J.ASOC.2020.106656

[22] Afandi, A. N., Miyauchi, H. "Improved artificial bee colony algorithm considering harvest season for computing economic dispatch on power system", IEEJ Transactions on Electrical and Electronic Engineering, 9(3), pp. 251-257, 2014. https://doi.org/10.1002/TEE.21963 
[23] Wei, W., Liu, F., Wang, J., Chen, L., Mei, S., Yuan, T. "Robust environmental-economic dispatch incorporating wind power generation and carbon capture plants", Applied Energy, 183, pp. 674-684, 2016.

https://doi.org/10.1016/j.apenergy.2016.09.013

[24] Yuan, G., Yang, W. "Study on optimization of economic dispatching of electric power system based on Hybrid Intelligent Algorithms (PSO and AFSA)", Energy, 183, pp. 926-935, 2019. https://doi.org/10.1016/j.energy.2019.07.008
[25] Afandi, A. N. "Thunderstorm Algorithm for Assessing Thermal Power Plants of the Integrated Power System Operation with an Environmental Requirement", International Journal of Engineering and Technology, 8(2), pp. 1102-1111, 2016.

[26] Wu, C., Gu, W., Jiang, P., Li, Z., Cai, H., Li, B. "Combined Economic Dispatch Considering the Time-Delay of District Heating Network and Multi-Regional Indoor Temperature Control", IEEE Transactions on Sustainable Energy, 9(1), pp. 118-127, 2018. https://doi.org/10.1109/TSTE.2017.2718031 